\title{
Chinese commentaries
}

\author{
Richard D. Weisel, MD
}

\footnotetext{
From the Division of Cardiovascular Surgery, Toronto General Hospital, Research Institute and the University of Toronto, Toronto, Ontario, Canada.

Disclosures: Author has nothing to disclose with regard to commercial support.

Address for reprints: Richard D. Weisel, MD, 200 Elizabeth St 4N-476, Toronto, Ontario, Canada M5G 2C4

(E-mail: rweisel@uhnresearch.ca).

J Thorac Cardiovasc Surg 2015;150:733

0022-5223/\$36.00

Copyright $(2015$ by The American Association for Thoracic Surgery

http://dx.doi.org/10.1016/j.jtcvs.2015.07.069
}

The Journal of Thoracic and Cardiovascular Surgery Chinese Edition (JTCVS CN Edition) was established in December 2010 with an editorial board of 32 members from the Executive Committee of the Chinese Society for Thoracic and Cardiovascular Surgery. Professor Shengshou $\mathrm{Hu}$ is the Editor of the Chinese edition, which is a bimonthly journal consisting of approximately 60 pages per issue. The parent journal is The JTCVS. The CN Edition editorial board selects manuscripts for translation from the parent journal to provide important information for the current clinical practice and interests of Chinese cardiothoracic surgeons. The $C N$ Edition provides advanced information, creating rich content for Chinese physicians and surgeons to appreciate the latest scientific and clinical advances in this specialty.

This year, the Chinese edition has been enhanced and upgraded. First, the mobile platform was improved to provide the journal content in the format most frequently used by Chinese cardiothoracic surgeons. Second, the central picture, central message, and perspective sections were added to the first page of the papers in the $C N$ Edition. Finally, Chinese commentaries were added to

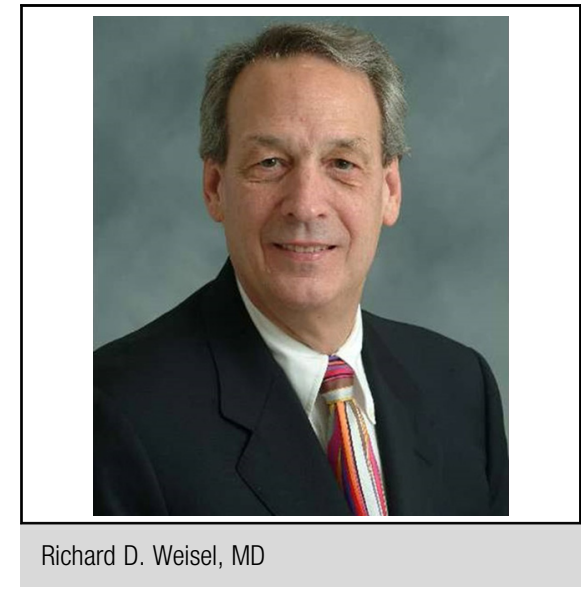

many of the papers selected for publication in the $C N$ Edition.

In this issue of the Journal are the English versions of 6 Chinese commentaries on papers published in the last issue of the CN Edition. We believe that these commentaries will provide valuable information for our readers. They indicate the reasons that the papers were selected for publication in the $C N$ Edition and the value that these papers provide for the Chinese surgeons. In addition, these commentaries provide an insight into the current state of the cardiothoracic surgery in China. Communication is essential to improve the care provided for our patients. Enhancing communication will fuel progress and advance the growth of our specialty. We hope that you enjoy the insights provided by the Chinese commentaries. 